\title{
(2) OPEN ACCESS \\ Illicit trade in tobacco products: recent trends and coming challenges
}

\author{
Guillermo Paraje $\odot,{ }^{1}$ Michal Stoklosa $\odot,{ }^{2}$ Evan Blecher ${ }^{3}$
}

'Business School, Universidad Adolfo Ibanez, Santiago de Chile, Chile

Institute for Health Research and Policy, University of Illinois at Chicago, Chicago, Illinois, USA

${ }^{3}$ Fiscal Policies for Health, World Health Organization, Geneva, Switzerland

Correspondence to Professor Guillermo Paraje, Business School, Universidad Adolfo Ibanez, Santiago de Chile, Chile;

guillermo.paraje@uai.cl

Received 31 May 2021 Accepted 26 July 2021
Check for updates

(c) Author(s) (or their employer(s)) 2022. Re-use permitted under CC BY-NC. No commercial re-use. See rights and permissions. Published by BMJ.

To cite: Paraje $\mathrm{G}$,

Stoklosa M, Blecher E.

Tob Control

$2022: 31: 257-262$

\section{ABSTRACT}

Background Illicit trade in tobacco products is a menace to the goal of eliminating tobacco consumption. Although tax policy is very effective in reducing consumption, illicit trade can reduce (though not eliminate) its effectiveness.

Methods This article discusses the recent evolution of illicit trade and the context in which it occurred; the new methods that have been developed to measure it and, finally, the challenges in the next phase in the control of illicit trade.

Results There has been a remarkable stability in the penetration of cigarette illicit trade in the past decade. Such a stability, however, occurred in a world of shrinking tobacco consumption, implying a decreasing absolute illicit trade. Most countries have progressed in increasing tobacco taxes and changing tax structures. Prices of illicit cigarettes follow legal cigarette prices. Concomitantly, many new studies, independent from the tobacco industry, have been conducted allowing for better understanding of the illicit trade and providing inputs to its solution. The entry into force of the WHO FCTC Protocol to Eliminate Illicit Trade in Tobacco Products provides both a global and a national policy framework to further curb illicit trade. Instruments such as track-and-trace systems must be promoted and adopted to maximise reductions in illicit trade.

Conclusions Global efforts to curb the illicit trade in tobacco products are gaining momentum and progress has been made in many parts of the world. The next decade can witness a decisive decrease in tobacco consumption, both licit and illicit, if countries further engage in international collaboration.

\section{INTRODUCTION}

A seminal article by Joossens et al estimated the illicit trade in cigarettes worldwide at $11.6 \%$ of the total market in $2007 .{ }^{1}$ The estimates ranged from $9.8 \%$ in the markets of high-income countries to $16.8 \%$ in those of low-income countries. Based on evidence from 84 countries, the authors provided information on the magnitude of the illicit cigarette trade at the global level, also highlighting the wide range of experiences between countries. At that time, illicit trade had evolved from largescale smuggling of well-known cigarette brands to more sophisticated types of illicit trade, including counterfeiting and the emergence of new cigarette brands produced at known locations and intended to supply the illicit market (the so-called 'illicit white' cigarettes). ${ }^{2}$

This article discusses the recent evolution of illicit trade and the tobacco-control context in which it occurred; the new methods that have been developed to measure it, independently from the tobacco industry (TI) and, finally, the likely challenges in the next phase in the control of illicit trade, framed by the adoption of the WHO FCTC Protocol to Eliminate Illicit Trade in Tobacco Products (ITP).

\section{THE RECENT EVOLUTION OF ILLICIT TRADE}

A recent estimate of global illicit trade in cigarettes by Goodchild $e t a l,{ }^{3}$ based on data from 36 countries, puts it at $11.2 \%$ of total consumption in the 2010-2018 period. There is also evidence that the proportion of 'illicit whites' stabilised during this period or was even reduced. ${ }^{4}$

Although findings from the studies by Joossens et $a l$ and Goodchild et al are not strictly comparable, as they cover different countries and use different methodologies, the similarity of the two estimates suggests a remarkable stability in the proportion of global illicit trade in the last decade.

However, the stability of results for illicit trade stands in contrast to underlying changes in consumption, use and tobacco control policies during the last decade. During this time, there has been a noticeable decrease in the global prevalence of smoking, which must be considered when analysing the evolution of illicit trade. Global prevalence of current smoking among those aged 15 years and older was $27.3 \%$ (43.2\% for males, $11.4 \%$ for females) in 2010 , as opposed to $23.6 \%$ (38.6\% for males, $8.5 \%$ for females) in $2018 .{ }^{5}$ Considering global population growth during this period, ${ }^{6}$ the decrease in prevalence means that there was a likely reduction in the number of smokers by about 4\% (consistent with what has been projected by $\mathrm{WHO}^{7}$ ). This is also consistent with estimates of the evolution of the global cigarette market by private companies. According to GlobalData, a market research company, the world's cigarette market declined from 5.8 trillion cigarette sticks in 2007 to 5.7 trillion sticks in 2015 and is predicted to fall to 4.6 trillion sticks by $2025 .^{8}$

The stability in the penetration of illicit trade in a context of a declining cigarette consumption would imply that the absolute volume of illicit trade has decreased. In essence, illicit cigarettes constitute, at most, a stable share of a shrinking market.

It is likely that factors behind the decrease in absolute cigarette consumption are the uptake of non-price measures, many of which would have suppressed demand for legal and illicit tobacco alike, ${ }^{9} 10$ and the reduction in the affordability of cigarettes. A way to measure affordability is by using the relative income price (RIP), which is the percentage of the per capita GDP required to buy 100 packs of cigarettes. ${ }^{11}$ The higher the RIP, the lower the affordability, as more income must be devoted to buy 100 packs of cigarettes. Using 
data from WHO for the price of the most-sold brand (in current international dollars, adjusted by power-purchase parity (PPP) $)^{12}$ and data from the World Bank for per capita GDP (in current international dollars, PPP) ${ }^{13}$ it can be seen that out of 168 countries with complete price data for 2008 and 2018, the RIP increased in 117 , which means that the cigarettes became less affordable. In 42 countries, the increase in the RIP was $>50 \%$, implying that average individuals had to devote at least $50 \%$ more of their income to buy 100 packs of the most-sold brand of cigarettes than in 2008. In 26 countries, the increase was $>100 \%$. However, increases in RIP were not uniform: of the 40 countries with the highest per capita GDP in 2018 (in international dollars, PPP), there were increases in RIP in 34 , and in 10 the increase was $>50 \%$. On the other hand, of the 40 countries with the lowest per capita GDP in 2018 (in international dollars, PPP), the RIP increased in 17 during this period, and only in 8 was such an increase $>50 \%$.

There is ample evidence that increases in tobacco taxes reduce affordability and tobacco consumption. ${ }^{14}{ }^{15}$ Behind the increase in RIP lie substantial increases in the rates of taxes on cigarettes and improvements in the structure of those taxes. The Tobacconomics Cigarette Tax Scorecard scores cigarette tax policy performance in over 170 countries on a 5 -point scale, providing policy makers with a useful assessment of their country's cigarette tax policy. The finding of the most recent report indicates that there has been an improvement in tax share scores over time, with the global average score rising from 1.91 in 2014 to 2.06 in 2018. In that period, tax share scores increased in 51 countries and fell in 28 . Tax structure scores have also slightly improved over time and 29 countries saw improvements in their tax structure score, while 9 countries saw their tax structure score fall between 2014 and $2018 .{ }^{16}$ The importance of this finding should not be understated. The TI has long argued that increases in taxes and prices (and by extension reductions in affordability) result in increases in illicit trade. The tax-induced declines in affordability contributed significantly to a declining cigarette market, and the reductions in demand for both legal and illicit cigarettes combined has meant that tobacco tax policy has likely contributed to a reduction in illicit cigarettes in absolute terms.

\section{TOBACCO CONTROL POLICIES AND ILLICIT TRADE}

The current evidence on the illicit trade in tobacco products is in stark contrast to the TI's claims. The findings imply that the global number of illicit cigarettes is falling contradict statements by the TI, which call the black market in tobacco 'a problem that is set to grow' ${ }^{17}$ and 'a serious and growing threat to society'. ${ }^{18}$ It has been established that the TI claims about the size of illicit market are, quite often, wildly exaggerated and misrepresented $^{19-22}$ and that studies presenting them have serious methodological limitations. ${ }^{23}$ Recent evidence shows that the transnational TI is responsible for the production of about twothirds of illicitly traded cigarettes. ${ }^{4}$

The evidence that tax increases are a leading predictor of illicit trade is also weak, even though the incentive to evade taxes presumably increases as the tax increases. For example, evidence suggests that countries with higher taxes have lower rates of illicit trade than countries with higher taxes. ${ }^{15}$ This may be the result of higher incentives to enforce tax compliance as tobacco taxes increase. An example of this is the UK where improvements in compliance have occurred in the last decade as taxes increased. ${ }^{24}$ Another example is the Philippines, where significant investment in tax administration occurred in conjunction with dramatic tax increases and reductions in affordability, which ensured that illicit trade declined rather than increased. ${ }^{25}$

What seems to determine the extent of illicit trade is the general capacity of tax administration authorities and levels of governance. Countries that struggle with tax compliance and/or governance, in general, are those most likely to experience high rates of illicit trade. This was evident in South Africa in recent years when illicit trade skyrocketed, coinciding with a dramatic decline in tax administration capacity and weakening governance of the South African Revenue Service and throughout government (often referred to as 'state capture') ${ }^{26}$ Notably, these increases in illicit trade were not accompanied by increases in taxes (in real terms) in contrast with periods of high tax increases which did not coincide with increases in illicit trade.

More recently, the TI has also used the illicit trade narrative to argue against non-tax policies, for example, the banning of menthol cigarettes or the implementation of plain or standardised packaging. Ostensibly, the argument is that the removal of menthol cigarettes from the legal market will simply mean that the demand for menthol cigarettes will remain unchanged, as it will be supplied by the black market. This argument is made without any evidence concerning the available supply chains for menthol cigarettes in the black market or of the capacity of authorities to control smuggling or illicit manufacturing. Evidence from Nova Scotia, Canada, showed no meaningful increase in the black market after the implementation of a menthol ban, even though menthol cigarettes were legally sold in other Canadian provinces. ${ }^{27}$ Recent evidence shows a relatively low rate of postban illicit menthol cigarette purchases between 2016 and 2018 in seven Canadian provinces. ${ }^{28}$

In the case of plain or standardised packaging, when it was first implemented in Australia, in 2012, the TI argued that illicit trade would surge as it would become more difficult to distinguish between legal and illegal packs, making them easier to counterfeit, and that the move would devalue brands, thereby encouraging the demand for cheaper, illicit cigarettes. ${ }^{29}$ Yet the industry's own estimates show that the volume of illicit cigarettes remained unchanged for many years after the introduction of plain packaging. ${ }^{30}$ The industry's claims were not supported by independent research and subsequent judicial findings have found them to be unfounded. ${ }^{31}$

\section{NEW METHODS TO MEASURE ILLICIT TRADE}

While neither the illicit market share nor the TI's rhetoric concerning illicit trade have substantially changed over the last decades, great progress has been made in our understanding of the illicit trade problem. How effectively governments can use tobacco taxes and other evidence-based policies aimed at reducing cigarette use as a public health issue, and as revenuegenerating measures, depends on how available the illicit tobacco products are. Therefore, the ability to estimate and to account for the illicit tobacco product market is critical in the design of more effective tax systems and in the formulation of other tobacco control regulations. Moreover, understanding the nature of the illicit trade in tobacco products is crucial to preventing it. Different forms of illicit trade might require different measures to tackle the problem. Therefore, studies aimed at estimating the scope and nature of illicit trade provide much-needed information to policymakers, law enforcement and other stakeholders involved in eliminating illicit trade in tobacco products.

Studying the illicit trade is, however, not easy, as trade in and consumption of illicit tobacco products is typically covert. Most governments do not conduct or commission their own studies on 
illicit trade and might rely on information provided by customs and other law enforcement agencies, in which case they will grasp only a fragmentary picture of the illicit cigarette problem or, even worse, rely on illicit trade estimates produced by or for the TI. In such cases, the information provided is likely to be distorted or exaggerated. ${ }^{23}$

In the last decade, comprehensive studies of the scope and nature of the illicit cigarette trade have increased. Since 2010, studies independent of the TI have been conducted in at least 40 countries. ${ }^{3}{ }^{32}$ Several methods, with their own advantages and limitations, ${ }^{33}$ have been used to analyse the entirety of the illicit trade problem, from a perspective independent of the TI.

One of the commonly used approaches involves using secondary data through gap analysis, where the illicit trade is estimated as a difference between survey-measured consumption and tax-paid sales. Although the gap analysis might not be viable in countries with no good tobacco use surveillance and in cases where some of the country's tax-paid cigarettes end up on the illegal market elsewhere, it has been used to discover trends in the illicit cigarette trade, for example, in five South American countries, ${ }^{34}$ South Africa ${ }^{35}$ and the Philippines. ${ }^{36}$

Other methods, allowing for more in-depth analysis of the illicit trade problem, involve primary data collection. Those techniques include littered pack collections (eg, Argentina ${ }^{37}$ and the USA ${ }^{38}$ ), purchasing packs from vendors (eg, India ${ }^{19}$ ) and pack examinations in smoker surveys (eg, Chile, ${ }^{21}$ Colombia $^{20} 3940$ and Georgia ${ }^{41}$ ). Some studies use a mix of two or more methods $\left(\right.$ Brazil $^{42}{ }^{4}$ Mexico ${ }^{43}$ and Pakistan ${ }^{44}$ ).

Importantly, some of these recent studies of the illicit trade in tobacco products were conducted as part of governments' concerted efforts to measure and understand the illicit trade in tobacco products. Perhaps the most comprehensive attempt to measure the illicit tobacco trade by any government is the UK's Measuring Tax Gaps report. ${ }^{45}$ The report has been published each year since 2001 and aims to measure revenue losses resulting from the illicit trade in tobacco products. By measuring illicit trade consistently over time, this effort helps evaluate the UK's anti-illicit strategies and assess their effectiveness. More recently, research from the Brazilian National Cancer Institute has used data from a telephone survey of smokers to assess the scope of illicit trade in the country and how it has changed over time. ${ }^{46}$ Officials from government organisations from Gambia and Mongolia coauthored studies on illicit trade in their countries. ${ }^{47} 48$ In Lithuania, a study, independent from the TI, was funded through a government grant. ${ }^{49}$

As the body of academic research on the illicit trade in tobacco products grew, so did the researchers' knowledge of how to conduct those studies effectively. Some aspects of the methods of these studies can prove to be tricky even for the most experienced researchers. For example, the sampling methods in the littered pack collections are not straightforward, while the surveys of smokers need to ask the right kind of questions to tease out information about illicit cigarette use. A recently published toolkit, written by the authors of this manuscript, attempts to gather the experience of the researchers who conducted studies on the illicit cigarette trade and to provide stepby-step instructions on how to plan and implement such studies in different settings. ${ }^{50}$

\section{TOBACCO PRICES AND ILLICIT TRADE}

Profit maximising smugglers imply that illicit cigarette prices increase along with the increases in legal prices. ${ }^{2}$ Some diverted demand from the legal market (consumers that choose to continue smoking instead of reducing smoking or quitting) pushes prices up in the illegal market, which, in turn, discourages smoking onset and/or makes some smokers to either quit or reduce smoking. ${ }^{3}$

Table 1 presents prices of legal and illegal cigarettes from studies, identified by Goodchild et al, from 2014 to 2020, as well as the most recent studies that we identified. ${ }^{32}{ }^{49}$ The table shows that, even when the prices are adjusted for purchasing power parity, the variation in illicit cigarette prices is large across the various countries, and the illicit cigarette prices generally follow the prices of legal cigarettes (correlation coefficient: $0.87) .{ }^{51}$ With average cigarette prices increasing worldwide, the price of illicit cigarettes increases as well, boosting the value of the illegal cigarette market, and decreasing demand for cigarettes (licit and illicit ones). A combination of shrinking demand and increased prices of illicit cigarettes increases the stakes for those involved in trading cigarettes illegally.

\section{THE PROTOCOL TO ELIMINATE ILLICIT TRADE IN TOBACCO PRODUCTS}

A decade ago, the control of illicit trade was, essentially, in the national realm. Efforts by organisations such as the World Customs Organization and Interpol existed, but these efforts were often sidelined by the broader priorities of the organisations. When the ITP entered into force in 2018, it opened new possibilities for controlling illicit trade in tobacco products. ${ }^{52} \mathrm{By}$ proposing a global mechanism to coordinate national efforts to address illicit trade, the ITP seeks to solve a common problem in the provision of global public goods: in the absence of a global coordinator/provider of the public good, such a provision is suboptimal if left decentralised. The ITP involves commitments by countries to implement an array of measures, including supply chain control, prosecution of offences and international cooperation to maximise global efforts to control illicit trade.

A cornerstone of these efforts is the adoption of track-andtrace systems (TTS) that enable monitoring of the movements of legal tobacco products and help authorities to determine at which point licit products become illicit. ${ }^{4}$ Eventually, the scope of the TTS should be extended to track key inputs, such as raw tobacco and filters. It has been argued that TTS can be a crucial tool for securing the tobacco supply chain, which has been singled out as the most effective intervention to curb illicit trade. ${ }^{53}$ Moreover, the ITP has a provision that it will establish a Global Information-Sharing Focal Point (GSP), to which ITP parties could make queries and receive information about product packs from other countries' TTS systems.

Unsurprisingly, the TI has attempted to influence and undermine governments' attempts to adopt effective TTS. ${ }^{4455}$ For instance, the Codentify system (rebranded Inexto) was developed by Philip Morris International (PMI) and later sold to a private company linked to former PMI executives while claiming to be independent. ${ }^{56}$ The system has been actively promoted as a reliable TTS to government bodies, despite the fact that it does not meet the obligations of independence from the TI as set out in the ITP ${ }^{54}$ and has been found highly inefficient as a valid TTS. $^{57}$

As more countries ratify the ITP, the ability to have a globally effective system for controlling the tobacco supply chain will only increase if countries are willing to share their information and economic intelligence. Adopting a TTS that works in isolation from the rest of the world or, even worse, is controlled or influenced by the TI, will not produce the intended effects.

ITP global tools, such as international cooperation and the TTS GSP, are critical for the effectiveness of other ITP 
Table 1 Prices of legal and illegal cigarettes in 2014-2021 from industry-independent studies

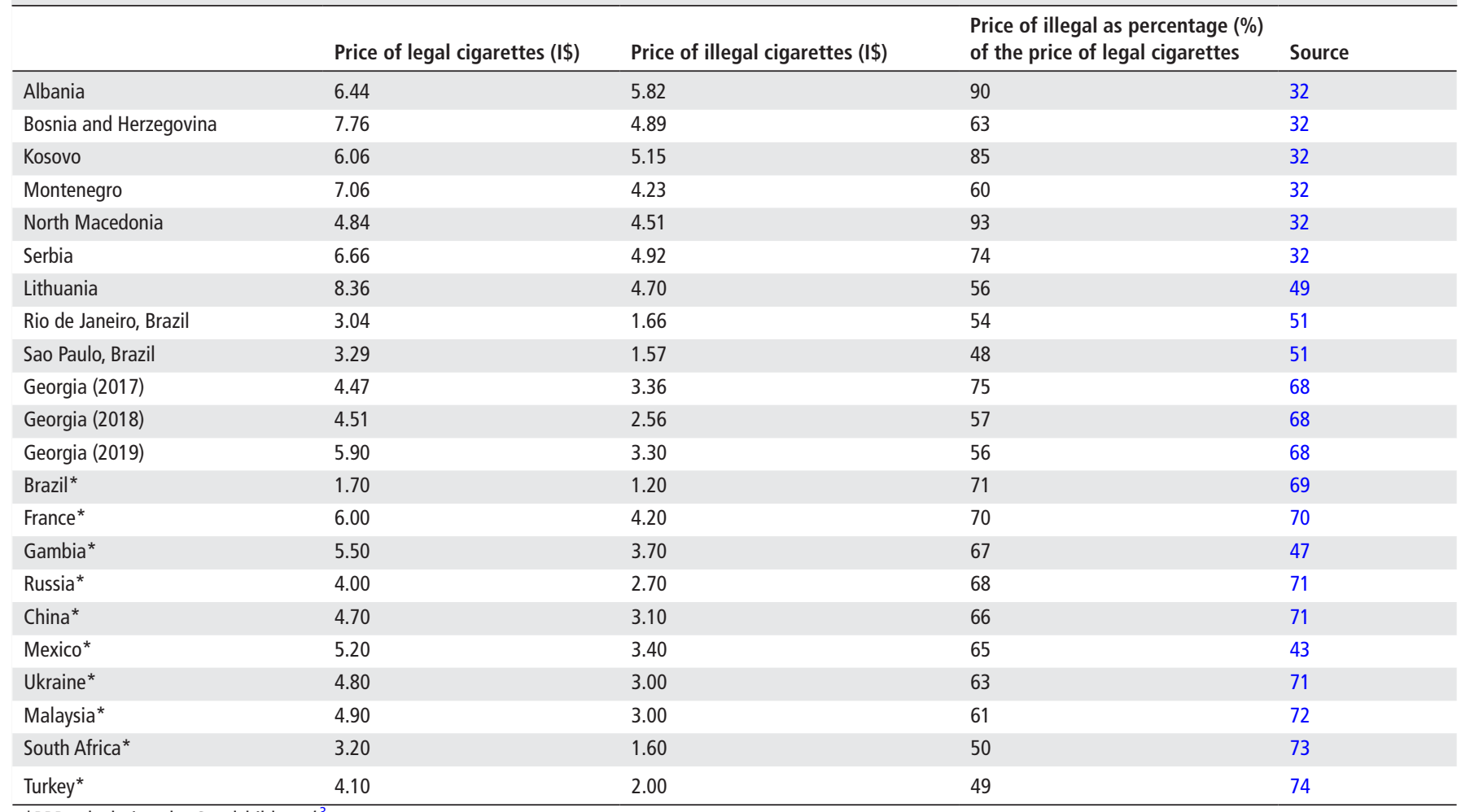

*PPP calculations by Goodchild et al. ${ }^{3}$

I\$, international dollars; PPP, power-purchase parity.

provisions, even those that are being implemented by parties individually. Seizure payments (Article 17 of the ITP) are a case in point. ${ }^{52}$ These payments, imposed on producers, manufacturers, distributors, importers or exporters if their tobacco, tobacco products and/or manufacturing equipment entered the illegal market and was seized by a law enforcement agency, are a way of punishing agents in the supply chain and deterring them from becoming involved in illicit trade, and also of incentivising all in the supply chain to exercise due diligence. Historically, enforcement of seizure payments was difficult, owing to the lack of reliable methods to classify seized cigarettes as counterfeit (not eligible for seizure-based payments) or genuine (eligible for the payments). ${ }^{55}$ The existence of a national/regional TTS with a GSP could facilitate and, in many cases, enable collection of the seizure payments. With the ability to find out from the system or the GSP the precise origin of the seized packs, ITP parties would effectively be able to impose seizure payments on the supply chain agents of seized tobacco products. In fact, a report by a panel of experts to the ITP has recommended the use of the TTS to identify those liable to seizure payments for their part in illicit trade. ${ }^{58}$

\section{THE CHALLENGES AHEAD}

Even if the number of illicit cigarettes is indeed falling, the world is far from ending the problem of the illicit trade in tobacco products. First, an important factor that hinders global progress in eliminating this trade is the scale and persistence of the problem in some areas of the world. One example of such illicit trade hot spot is Paraguay. It is well documented that Paraguayan manufacturers have been a major source of illicit cigarettes to Latin America and the rest of the world since the mid-1990s. ${ }^{59}$ Twenty years later, these manufacturers still supply the market with quantities of cigarettes that are seven times greater than could be explained by Paraguay's local demand and legitimate cigarette exports. ${ }^{60}$ As a result, an overwhelming majority of foreign illicit cigarette packs consumed in Brazil and Argentina come from Paraguay. ${ }^{3742}$ In 2017, the illicit market share in Brazil was about six times higher than in Colombia, a country with lower incomes, higher cigarette prices, but located further away from Paraguay. ${ }^{3946}$ Similarly, while the Jebel Ali Free Trade Zone in the United Arab Emirates (UAE) was identified as a major source of illicit cigarettes over a decade ago, ${ }^{61}$ it continues to supply illicit cigarettes to markets in Europe. ${ }^{62} \mathrm{New}$ illicit trade hot spots emerge, as the recent proliferation of illicit cigarette factories in the European Union (EU) suggests. ${ }^{63}$

Second, the types of tobacco products traded illegally also change, which poses enforcement problems. According to reports by the World Customs Organization, cigarettes remain the main tobacco products seized globally. ${ }^{64}$ However, some new products are beginning to emerge on the illicit market. For instance, seizures of water pipe tobacco accounted for $<1 \%$ of all tobacco product seizures globally in 2012. The figure has gradually increased to over $6 \%$ in $2019 .{ }^{64} 65$ Similarly, while in 2012 seizures of electronic cigarettes and cartridges were nonexistent, the category accounted for $7 \%$ of all tobacco product seizures in 2019. ${ }^{64} 65$ The illicit trade in other tobacco products, especially in novel tobacco products, should not be neglected. For example, the 2019 EVALI crisis in the USA was linked to illicit electronic cigarettes and cartridges. ${ }^{66}$

There are also challenges related to countries' capacity to implement ITP provisions. Successful ITP implementation requires parties to modify, often extensively, their legal, administrative and enforcement structures. Yet these parties often lack substantial understanding of the ITP across all relevant sectors of government. They also often lack capacity to oppose the industry interference in the implementation process. Therefore, specialised technical 
assistance will be needed to build domestic capacities to a level that they can fully implement the protocol. There is an urgent need for the protocol's secretariat to help building those capacities, while establishing the GSP that will allow for a seamless exchange of information between the parties. Although it is an investment with a potential high rate of return, financial support will also often be needed to cover the initial investment required to implement the TTS, especially in low-income and middle-income countries. Finally, more in-country research is needed on the impacts and effectiveness of ITP interventions.

Despite these challenges, global efforts to curb the illicit trade in tobacco products are gaining momentum and progress has been made in many parts of the world. ${ }^{67}$ Progress was made when higher cigarette taxes and other tobacco-control measures were implemented. TTS operates in all 27 members of the EU, plus at least 14 other countries (Albania, Bahamas, Brazil, Canada, Chile, Ecuador, Kenya, Kosovo, Morocco, Saudi Arabia, Turkey, UAE, Uganda and the UK) and the most populous US state, California. At least 14 other countries have systems that include fiscal marking of cigarettes and that could be used as a first step to adopt a full TTS. Many more countries are reviewing the possibility of using TTS mechanisms, including India. Exchange of information between the systems in the EU is seamless, and other groups of countries (eg, Uganda and Kenya) are discussing information exchange between their systems even before the GST is fully functional. To implement ITP provisions, many countries (eg, the UK, the Netherlands) establish intersectoral working groups to address the illicit trade problem holistically, while the ITP working group on assistance and cooperation lays the groundwork for swift and effective cooperation between countries. With the platform of the ITP in place, further progress in tackling the illicit tobacco trade can be made.

What this paper adds

- This work critically discusses the evolution of tobacco illicit trade over the last decade and explains the policy context in which it occurred.

- This work highlights the proliferation of studies, independent from the tobacco industry, that measure illicit trade and provide guidance to authorities to curb such a trade.

- This work critically discusses the challenges and necessary next steps that countries must take to further control illicit trade.

- The wide adoption of the WHO FCTC Protocol to Eliminate Illicit Trade in Tobacco Products is discussed as a necessary though not a sufficient condition to achieve such a goal.

\section{Twitter Guillermo Paraje @gparaje}

Acknowledgements We thank Elizabeth Baldwin for her editing assistance and Mauricio Muñoz Flores for his research assistance. The usual disclaim applies.

Contributors All authors have contributed equally to the writing of this manuscript.

Competing interests None declared.

Patient consent for publication Not required.

Provenance and peer review Commissioned; externally peer reviewed.

Data availability statement No data are available. No data have been used.

Open access This is an open access article distributed in accordance with the Creative Commons Attribution Non Commercial (CC BY-NC 4.0) license, which permits others to distribute, remix, adapt, build upon this work non-commercially, and license their derivative works on different terms, provided the original work is properly cited, appropriate credit is given, any changes made indicated, and the use is non-commercial. See: http://creativecommons.org/licenses/by-nc/4.0/.

\section{ORCID iDs}

Guillermo Paraje http://orcid.org/0000-0002-7863-907X

Michal Stoklosa http://orcid.org/0000-0003-2014-539X

\section{REFERENCES}

1 Joossens L, Merriman D, Ross H, et al. The impact of eliminating the global illicit cigarette trade on health and revenue. Addiction 2010;105:1640-9.

2 Joossens L, Raw M. From cigarette smuggling to illicit tobacco trade. Tob Control 2012:21:230.

3 Goodchild M, Paul J, Iglesias R, et al. Potential impact of eliminating illicit trade in cigarettes: a demand-side perspective. Tob Control 2020:tobaccocontrol2020-055980.

4 Gilmore AB, Gallagher AWA, Rowell A. Tobacco industry's elaborate attempts to control a global track and trace system and fundamentally undermine the Illicit Trade Protocol. Tobacco Control 2018.

5 The World Health Organization. WHO health data. Available: http://www.who.int/gho/

6 United Nations Department of Economic and Social Affairs. World population prospects 2019 2021. Available: https://population.un.org/wpp/Download/Standard/ Population/

7 World Health Organisation. WHO global report on trends in prevalence of tobacco use 2000-2025, third edition. Geneva, Switzerland World Health Organization; 2019.

8 GlobalData. Sector databases. London, UK; 2020.

9 Apollonio DE, Dutra LM, Glantz SA. Associations between smoking trajectories, smoke-free laws and cigarette taxes in a longitudinal sample of youth and young adults. PLoS One 2021;16:e0246321.

10 International Agency for Research on Cancer. Evaluating the effectiveness of smokefree policies. The World Health Organization: Lyon, 2009.

11 Blecher EH, van Walbeek CP. An international analysis of cigarette affordability. Tob Control 2004;13:339-46.

12 The World Health Organisation. Who report on the global tobacco epidemic, 2019. Geneva2019 2019.

13 The World Bank. The World Bank Database [Available from. Available: http://data. worldbank.org [Accessed Access date: 31 March 2021].

14 International Agency for Research on Cancer. Effectiveness of Tax and price policies for tobacco control. The World Health Organization: Lyon, 2011.

15 U.S. National Cancer Institute, The World Health Organization. The economics of tobacco and tobacco control 2016

16 Chaloupka F, Drope J, Siu E, Vulovic V, Stoklosa M, Mirza M. Tobacconomics cigarette Tax scorecard. Chicago, IL; 2020.

17 British American Tobacco. Illegal tobacco trade, 2020. Available: https://www.bat com/theman

18 Phillip Morris International. Illicit tobacco trade prevention, 2020. Available: https:// www.pmi.com/integrated-report-2019/operating-with-excellence/illicit-tobacco-tradeprevention

19 John RM, Ross H. Illicit cigarette sales in Indian cities: findings from a retail survey. Tob Control 2018:27:684

20 Maldonado N, Llorente BA, Iglesias RM, et al. Measuring illicit cigarette trade in Colombia. Tob Control 2020:29:s260-6.

21 Paraje G, Araya D, Drope J. Illicit cigarette trade in metropolitan Santiago de Chile. Tob Control 2020;29:68-73.

22 Stoklosa M, Ross H. Contrasting academic and tobacco industry estimates of illicit cigarette trade: evidence from Warsaw, Poland. Tob Control 2014;23:e30.

23 Gallagher AWA, Evans-Reeves KA, Hatchard JL, et al. Tobacco industry data on illicit tobacco trade: a systematic review of existing assessments. Tob Control 2019:28:334-45.

24 Blecher E. Case studies in illicit tobacco trade. United Kingdom University of Illinois at Chicago; 2020.

25 Diosana J, Sta Ana FS III. Case studies in illicit tobacco trade. The Philippines University of Illinois at Chicago; 2020.

26 van Walbeek C. Case studies in illicit tobacco trade. South Africa University of Illinois at Chicago; 2020

27 Stoklosa M. No surge in illicit cigarettes after implementation of menthol ban in nova Scotia. Tob Control 2019:28:702

28 Chung-Hall J, Fong GT, Meng G, et al. Evaluating the impact of menthol cigarette bans on cessation and smoking behaviours in Canada: longitudinal findings from the Canadian arm of the 2016-2018 ITC four country smoking and Vaping surveys. Tob Control 2021. doi:10.1136/tobaccocontrol-2020-056259. [Epub ahead of print: 05 Apr 2021].

29 Scollo M, Zacher M, Durkin S, et al. Early evidence about the predicted unintended consequences of standardised packaging of tobacco products in Australia: a crosssectional study of the place of purchase, regular brands and use of illicit tobacco. BMJ Open 2014:4:e005873.

30 KPMG LLP. Illicit tobacco in Australia (2019 full year report). London, UK; 2020 
31 Scollo M, Zacher M, Coomber K, et al. Use of illicit tobacco following introduction of standardised packaging of tobacco products in Australia: results from a national cross-sectional survey. Tob Control 2015;24:ii76.

32 Vladisavljević M, Đukić M, Zubović J, Jovanović O, Jolović N. Tobacco Tax evasion in southeastern Europe: Tax evasion prevalence and evasion determinants. Belgrade, Serbia; 2021.

33 Ross H. Understanding and measuring cigarette Tax avoidance and evasion. A methodological guide, 2015. Available: http://tobaccoecon.org/publications/reports/

34 Paraje G. Illicit cigarette trade in five South American countries: a gap analysis for Argentina, Brazil, Chile, Colombia, and Peru. Nicotine Tob Res 2019;21:1079-86.

35 Vellios N, van Walbeek C, Ross H. Illicit cigarette trade in South Africa: 2002-2017. Tob Control 2020;29:s234.

36 Lavares MP, Ross H, Francisco A, et al. Analysing the trend of illicit tobacco in the Philippines from 1998 to 2018. Tob Control 2021. doi:10.1136/ tobaccocontrol-2020-056253. [Epub ahead of print: 19 Feb 2021].

37 Pizarro ME, Giacobone G, Shammah C, et al. Illicit tobacco trade: empty pack survey in eight Argentinean cities. Tob Control 2021. doi:10.1136/ tobaccocontrol-2020-056405. [Epub ahead of print: 08 Apr 2021].

38 Barker DC, Wang S, Merriman D, et al. Estimating cigarette Tax avoidance and evasion: evidence from a national sample of littered packs. Tob Control 2016;25:i38.

39 Maldonado N, Llorente B, Escobar D, et al. Smoke signals: monitoring illicit cigarettes and smoking behaviour in Colombia to support tobacco taxes. Tob Control 2020;29:s243-8.

40 Gallego JM, Llorente B, Maldonado N, et al. Tobacco taxes and illicit cigarette trade in Colombia. Econ Hum Biol 2020;39:100902.

41 Little M, Ross H, Bakhturidze G, et al. Illicit tobacco trade in Georgia: prevalence and perceptions. Tob Control 2020;29:s227.

42 Szklo AS, Iglesias RM, Stoklosa M, et al. Cross-Validation of four different survey methods used to estimate illicit cigarette consumption in Brazil. Tob Control 2022;31:73-80.

43 Saenz de Miera Juarez B, Reynales-Shigematsu LM, Stoklosa M, et al. Measuring the illicit cigarette market in Mexico: a cross validation of two methodologies. Tob Control 2021;30:125-31.

44 Khan A, Dobbie F, Siddiqi K, et al. Illicit cigarette trade in the cities of Pakistan: comparing findings between the consumer and waste recycle store surveys. Tob Control 2021. doi:10.1136/tobaccocontrol-2020-056386. [Epub ahead of print: 15 Apr 2021].

45 HM Revenue \& Customs. Measuring Tax gaps 2020 edition. Tax gap estimates for 2018 to 2019. London, UK HM Revenue \& Customs,; 2020.

46 Szklo AS, Iglesias RM. Decrease in the proportion of illicit cigarette use in Brazil: what does it really mean? Tob Control 2020;29:s287.

47 Chisha Z, Janneh ML, Ross H. Consumption of legal and illegal cigarettes in the Gambia. Tob Control 2020:29:s254.

48 Ross H, Vellios N, Batmunkh T, et al. Impact of Tax increases on illicit cigarette trade in Mongolia. Tob Control 2020;29:s249.

49 Liutkute-Gumarov V, Galkus L, Petkevičienè J, et al. Illicit tobacco in Lithuania: a crosssectional survey. Int J Environ Res Public Health 2020;17:7291.

50 Stoklosa M, Paraje G, Blecher E. A toolkit on measuring illicit trade in tobacco products. Chicago University of Illinois; 2020.

51 Figueiredo C V, Drope J, Iglesias R. Consumo de cigarros ilegais em cinco cidades brasileira 2021.

52 The World Health Organization Framework Convention on Tobacco Control. Protocol to eliminate illicit trade in tobacco products. Geneva, Switzerland; 2013.
53 Solutions SB, Ross H. FCTC Protocol to Eliminate Illicit Trade in Tobacco Products Guidebook on Implementing Article 8: Tracking \& Tracing 2019.

54 Gallagher AWA, Gilmore AB, Eads M. Tracking and tracing the tobacco industry: potential tobacco industry influence over the EU's system for tobacco traceability and security features. Tob Control 2020;29:e56.

55 Joossens L, Gilmore AB, Stoklosa M, et al. Assessment of the European Union's illicit trade agreements with the four major transnational tobacco companies. Tob Control 2016:25:254.

56 Joossens L. Traceability: the tobacco industry is part of the problem, not the solution. Tob Control 2019;28:121

57 Ross H, Eads M, Yates M. Why governments cannot afford Codentify to support their track and trace solutions. Tob Control 2018;27:706

58 WHO FCTC Secretariat. Report of the panel of experts on the protocol to eliminate illicit trade in tobacco products. Geneva, Switzerland WHO FCTC Secretariat; 2020.

59 Iglesias RM, Gomis B, Carrillo Botero N, et al. From transit hub to major supplier of illicit cigarettes to Argentina and Brazil: the changing role of domestic production and transnational tobacco companies in Paraguay between 1960 and 2003. Global Health 2018;14:111.

60 Masi F, Cresta J, Ovando F, et al. Tobacco oversupply in Paraguay and its Cross-border impacts. Asunción, Paraguay: Centro de Análisis y Difusión de la Economía Paraguaya (CADEP), 2021

61 Holden C. Graduated sovereignty and global governance gaps: special economic zones and the illicit trade in tobacco products. Polit Geogr 2017;59:72-81.

62 Deutsche Welle. Cigarette smuggling in the UAE an EU headache, 2019. Available: https://www.dw.com/en/cigarette-smuggling-in-the-uae-an-eu-headache/a50930382\#: :text=Firms\%20in\%20the\%20United\%20Arab,elsewhere\%2C\% 20as\%20Stian\%200verdahl\%20reports

63 European Union Agency for Law Enforcement Cooperation. Illicit tobacco trade, 2021 Available: https://www.europol.europa.eu/crime-areas-and-trends/crime-areas/illicittobacco-trade

64 World Customs Organization. Illicit trade report 2019. Brussels, Belgium; 2020.

65 World Customs Organization. Illicit trade report 2012. Brussels, Belgium; 2013.

66 Pray IW, Atti SK, Tomasallo C, et al. E-cigarette, or Vaping, Product Use-Associated Lung Injury Among Clusters of Patients Reporting Shared Product Use - Wisconsin, 2019. MMWR Morb Mortal Wkly Rep 2020;69:236-40.

67 Dutta S. Confronting illicit tobacco trade. A global review of country experiences. Washington DC The World Bank; 2019.

68 Little M, Ross H, Bakhturidze G, et al. Analysis of the illicit tobacco market in Georgia in response to fiscal and non-fiscal tobacco control measures. Tob Control 2021. doi:10.1136/tobaccocontrol-2020-056404. [Epub ahead of print: 10 Jun 2021].

69 Iglesias RM, Szklo AS, Souza MCde, et al. Estimating the size of illicit tobacco consumption in Brazil: findings from the global adult tobacco survey. Tob Control 2017;26:53-9.

70 Joossens L, Lugo A, La Vecchia C, et al. Illicit cigarettes and hand-rolled tobacco in 18 European countries: a cross-sectional survey. Tob Control 2014;23:e17.

71 Brown J, Welding K, Cohen JE, et al. An analysis of purchase price of legal and illicit cigarettes in urban retail environments in 14 low- and middle-income countries. Addiction 2017:112:1854-60

72 Liber AC, Ross H, Omar M, et al. The impact of the Malaysian minimum cigarette price law: findings from the ITC Malaysia survey. Tob Control 2015;24 Suppl 3:iii83.

73 van der Zee K, Vellios N, van Walbeek C, et al. The illicit cigarette market in six South African townships. Tob Control 2020;29:s267-74.

74 Kaplan B, Navas-Acien A, Cohen JE. The prevalence of illicit cigarette consumption and related factors in turkey. Tob Control 2018;27:442. 